\title{
La importancia del guion instruccional en el diseño de ambientes virtuales de aprendizaje ${ }^{1}$
}

\author{
Aida Gómez ${ }^{2}$ \\ Universidad Jorge Tadeo Lozano.
}

Recibido, mayo 09 de 2017

Evaluado, junio 26 de 2017

Aceptado, junio 30 de 2017
Referencia: Gómez, A. (2017). "La importancia del guion instruccional en el diseño de ambientes virtuales de aprendizaje". Revista Academia y Virtualidad, 10, (2), 47-60

\section{Resumen}

La apropiación de las tecnologías de la información y las comunicaciones (TIC), en los procesos de la enseñanza-aprendizaje, es uno de los principales desafíos de las instituciones educativas y de los docentes en la actual sociedad de conocimiento, como responsables de un uso racional y significativo de sus recursos educativos digitales (RED). Esto implica desarrollar competencias en la implementación de las TIC en el aula para enriquecer los ambientes de aprendizaje. En este artículo se presenta una reflexión sobre el guion instruccional como herramienta didáctica en la elaboración de RED que facilita el diseño de estos recursos para apoyar las actividades de la clase presencial en dichos procesos. Esta reflexión es resultado de una investigación sobre el tema realizada en un contexto de docencia universitaria.

Palabra clave: tecnología, formación docente, competencias, recursos educativos digitales, guion instruccional.

\footnotetext{
${ }^{1}$ Artículo de reflexión Este artículo es resultado de la investigación hecha por la autora de su tesis de maestría en Informática Educativa, titulada Recurso Educativo Digital como Herramienta Didáctica para la Elaboración del Guión Instruccional, aprobada por la Universidad de la Sabana.

${ }^{2}$ Diseñadora gráfica, especialista en edición digital y multimedia, especialista en entornos virtuales de aprendizaje, magister en informática educativa. Profesora asociada II. Universidad Jorge Tadeo Lozano. E-mail: aida.gomez@utadeo.edu.co
} 


\title{
The importance of the instructional guide in the design of virtual learning environments
}

\begin{abstract}
The appropriation of information and communication technologies (ICTs) in the processes of teaching and learning is one of the main challenges of educational institutions and teachers in the current society of knowledge, as responsible for a use Rational and meaningful use of its digital educational resources (RED). This involves developing competencies in the implementation of ICT in the classroom to enrich the learning environments. This article presents a reflection on the instructional guide as a didactic tool in the elaboration of RED that facilitates the design of these resources to support the activities of the classroom in these processes. This reflection is the result of a research on the subject carried out in a context of university teaching.
\end{abstract}

Keywords: technology, teacher training, competencies, digital educational resources, instructional guide.

\section{A importância da guia instrucional no design de ambientes virtuais de aprendizagem}

\section{Resumo}

A apropriação das tecnologias da informação e as comunicações (TIC), nos processos de ensino-aprendizagem, é um dos principais desafios das instituições educativas e dos docentes na atual sociedade de conhecimento, como responsáveis de um uso racional e significativo de seus recursos educativos digitais (RED). Isto implica desenvolver habilidades na implementação das TIC na sala de aula para enriquecer os ambientes de aprendizagem. Neste artigo se apresenta uma reflexão sobre a guia instrucional como ferramenta didática na elaboração de RED que facilita o design destes recursos para apoiar as atividades da aula presencial nestes processos. Esta reflexão é resultado de uma pesquisa sobre o tema realizada em um contexto de docência universitária.

Palavras chave: tecnologia, formação docente, habilidades, recursos educativos digitais, guia instrucional. 


\section{Introducción}

La Organización de las Naciones Unidas para la Educación, la Ciencia y la Cultura (Unesco) ha hecho una serie de declaraciones sobre la importancia de la implementación de las TIC en la educación, entre las que se destaca la siguiente:

Hoy en día, los docentes en ejercicio necesitan estar preparados para ofrecer a sus estudiantes oportunidades de aprendizaje apoyadas en las TIC; para utilizarlas y para saber cómo éstas pueden contribuir al aprendizaje de los estudiantes, capacidades que actualmente forman parte integral del catálogo de competencias profesionales básicas de un docente (Unesco, 2008, p.2).

En el mismo documento, en su prefacio, se afirma que el docente "es el responsable de diseñar tanto oportunidades de aprendizaje como el entorno propicio en el aula que faciliten el uso de las TIC por parte de los estudiantes" (Unesco, 2008, p. 2 ), y uno de los objetivos principales del "Proyecto estándares Unesco de competencias en TIC para docentes (ECD-TIC)" es "elaborar un conjunto común de directrices que los proveedores de formación profesional puedan utilizar para identificar, desarrollar o evaluar material de aprendizaje o programas de formación de docentes con miras a la utilización de las TIC en la enseñanza y el aprendizaje" (Unesco, 2008, p. 4). Con estas declaraciones la Unesco enmarca la reflexión sobre la relación entre la educación y las tecnologías que caracterizan a la sociedad del conocimiento.

La Unesco afirma que "los docentes necesitan estar preparados para empoderar a los estudiantes con las ventajas que les aportan las TIC. Escuelas y aulas -ya sean presenciales o virtuales-deben contar con docentes que posean las competencias y los recursos necesarios en materia de TIC" (2008, p.2).

Por su parte, el "ProgramaNacionalde Uso de
Medios y Nuevas Tecnologías" del Ministerio de Educación Nacional (MEN) plantea como objetivo "promover el uso y apropiación de las Tecnologías de Información y Comunicación al servicio del mejoramiento de la calidad y equidad de la educación y la competitividad de las personas y del país" (MEN, 2008). Este objetivo señala el alcance e importancia de las TIC en las aulas de clase; sin embargo, la preparación en el uso y apropiación de las TIC en los docentes de instituciones de educación superior resulta insuficiente, lo que implica que no están preparados para aprovechar las herramientas digitales y que los planes de estudio se tratan de forma aislada a las novedades tecnológicas, limitando el uso de estas por parte del estudiante en la práctica extracurricular.

Para dar respuesta a esta problemática en la investigación, algunos de cuyos resultados se exponen en este artículo, se diseñó, desarrolló e implementó un guion instruccional para la elaboración de recursos educativos digitales, con la finalidad de brindarle al docente conocimientos adecuados en relación con la integración de contenidos temáticos en una asignatura y su dinamización mediante el uso TIC, como apoyo a la clase presencial.

\section{Competencias docentes en tecnologías de la información y las comunicaciones}

El Ministerio de Educación Nacional (MEN), define 'competencia' como el conjunto de conocimientos, habilidades, actitudes, comprensiones y disposiciones cognitivas, socio-afectivas y psicomotoras apropiadamente relacionadas entre sí para facilitar el desempeño flexible, eficaz y con sentido de una actividad en contextos relativamente nuevos y retadores (MEN, 2013, p.29).

En el documento "Competencias TIC para el desarrollo profesional docente, el MEN afirma que las "competencias se han constituido en 
el eje articulador del sistema educativo en Colombia" (MEN, 2013, p. 29), y define las competencias que deben desarrollar los docentes en cinco tipos:

Competencia tecnológica: consiste en la capacidad para seleccionar y utilizar de forma pertinente, responsable y eficiente una variedad de herramientas tecnológicas entendiendo los principios que las rigen, la forma de combinarlas y su utilización en el contexto educativo. / Competencia comunicativa: consiste en la capacidad para expresarse, establecer contacto y relacionarse en espacios virtuales y audiovisuales a través de diversos medios y con el manejo de múltiples lenguajes, de manera sincrónica y asincrónica. / Competencia pedagógica: consiste en la capacidad de utilizar las TIC para fortalecer los procesos de enseñanza y aprendizaje, reconociendo alcances y limitaciones de la incorporación de estas tecnologías en la formación integral de los estudiantes y en su propio desarrollo profesional. / Competencia de gestión: consiste en la capacidad para utilizar las TIC, de manera efectiva, en la planeación, organización, administración y evaluación de los procesos educativos; tanto a nivel de prácticas pedagógicas como de desarrollo institucional. / Competencia investigativa: consiste en la capacidad para utilizar de manera efectiva las TIC en la planeación, organización, administración y evaluación de los procesos educativos; tanto a nivel de prácticas pedagógicas como de desarrollo institucional (MEN, 2013, p. 29).

Al leer con detenimiento la descripción de cada una de las anteriores competencias, se evidencia claramente el papel tan importante que juegan las TIC en cada uno de los factores que hacen parte de todo proceso educativo, no solo a nivel académico sino también a nivel administrativo, y da soporte a la necesidad de que las instituciones educativas las integren en sus dinámicas educativas y administrativas.

Es muy importante para la institución escolar de cada país, que las nuevas tecnologías se integren adecuadamente, y dentro de sus posibilidades, en sus dinámicas educativas, administrativas, culturales, etc. Son herramientas poderosas que deben ponerse al alcance de todos los individuos (Campuzano, 1992, p.12).

\section{Las TIC como apoyo al aprendizaje}

La necesidad de comunicarse y de aprender se ha ido transformando con la implementación de las tecnologías en las diferentes áreas del conocimiento. En la educación, las TIC han generado transformaciones en la forma de enseñar y aprender; los estudiantes se convierten en individuos autónomos y con el uso de las múltiples herramientas TIC, el docente tiene la posibilidad de generar aprendizaje colaborativo y participativo, permitiéndole al estudiante construir significativamente conocimiento y dándole herramientas para el desarrollo de actividades autónomas.

Es indispensable que los docentes tengan un conocimiento claro sobre qué son las TIC y cómo pueden contribuir en su labor, además de conocer las múltiples herramientas que existen y cómo usarlas; pues, teniendo un manejo idóneo de ellas es más sencilla su implementación e integración en cada uno de los procesos pedagógicos en los que participe, brindándoles a los estudiantes diferentes posibilidades de aprender, tanto a nivel grupal como individual.

Dentro de los procesos educativos el docente debe ser un guía, un tutor que oriente las diferentes actividades educativas, para lo cual puede implementar diversos recursos tecnológicos que le permitirán enriquecer el trabajo en clase, para ofrecerle al estudiante espacios de interacción y reflexión que le posibiliten la toma de decisiones y la construcción de conocimientos.

Para los estudiantes, el uso de esta clase de herramientas es favorable, debido a la posibilidad de acceder a mayor cantidad de información en menor tiempo; estas ayudas 
tecnológicas, a su vez, les ofrecen también calidad de información de forma didáctica y multimedial, permitiéndoles comprender con mayor facilidad temas específicos que, en ocasiones, no logran asimilar dentro del aula de clase; también les da la posibilidad de elegir de forma personalizada y autónoma los contenidos que se acerquen más a sus necesidades e intereses.

El concepto de autonomía para Piaget significa llegar a ser capaz de pensar por sí mismo con sentido crítico, teniendo en cuenta muchos puntos de vista, tanto en el ámbito moral como en el intelectual; la finalidad de la educación debe ser el desarrollo de la autonomía (Piaget, 1932).

Para Rúa, "el aprendizaje autónomo puede conceptualizarse como el acceso del ser a sus más altos deseos de promoción y avance haciendo uso consciente de sus potencialidades $y$ de los elementos del contexto de manera razonada, audaz y persistente” (1998, p.20).

El concepto de autonomía en Colombia cobra aún más validez con la formulación del Decreto 1075 de 2015 del MEN con respecto al sistema de créditos académicos en la educación superior y su relación con el desempeño independiente del estudiante. Según el Decreto, por cada hora de clase presencial el estudiante debe dedicar dos horas de trabajo individual, en programas de pregrado $\mathrm{y}$ de especialización, $\mathrm{y}$ tres en programas de maestría (Capítulo 2, Sección 4, Artículo 2.5.3.4.2), es por tal motivo que los planes de estudio deben incorporar las mediaciones pedagógicas que permitan dinamizar el uso de la tecnología y de las ayudas didácticas para el aprendizaje autónomo del estudiante.

El propósito del Decreto, por su mismo alcance e interpretación, es un primer paso en la valoración del trabajo independiente para alcanzar un cambio en la educación superior en Colombia que esté en verdadera sintonía con los cambios del contexto mundial (Zambrano, 2008). Para Zambrano, este contexto se caracteriza por un nuevo rol del docente, en el cual el aprendizaje se centra en el estudiante y la autonomía es el eje en el que convergen junto con el saber (2008).

El aprendizaje autónomo, a través de un recurso educativo digital, propicia en el estudiante un aprendizaje autorregulado. En la educación virtual, el estudiante prácticamente depende de este para su aprendizaje por tratarse de un material "autocontenible $y$ reutilizable, con un claro propósito educativo, constituido por al menos tres componentes internos editables como contenidos, actividades de aprendizaje y elementos de contextualización" (Laverde, Cifuentes y Rodríguez., 2007, p.671). En comparación con esta, los recursos educativos digitales en la educación presencial pueden presentar diferentes dinámicas; primero porque se convierte en un eje articulador entre el estudiante y el profesor, y segundo, porque no necesariamente deben contemplar actividades o evaluaciones, como sí se deben contemplar en un recurso para la educación virtual. Un buen ejemplo es el concepto de aula invertida. Esta dinámica supone un desplazamiento intencional fuera del aula de determinadas partes del contenido de las asignaturas. A través de actividades guiadas y determinados recursos (videos, textos, contenidos digitales) se transfiere intencionalmente fuera del aula parte de la información que el profesor tiene que transmitir con el fin de liberar tiempo de la clase para dedicarlo a actividades de aprendizaje en las que la presencia del docente es imprescindible (Medina, 2012, párr. 1).

En este escenario los recursos educativos digitales son más flexibles, son más específicos y propenden al aprendizaje significativo en los estudiantes, ya que este se hace partícipe de su propio proceso de aprendizaje; la clase deja de estar centrada en el profesor y pasa a estar centrada en el estudiante. 


\section{El rol del docente en el diseño de recursos educativos digitales}

Las instituciones educativas le delegan el diseño de material educativo al docente; sin embargo, muchos de ellos no poseen competencias en el uso de herramientas digitales y mucho menos poseen competencias en diseño para la producción de estos. $\mathrm{La}$ elaboración de recursos educativos digitales debe recorrer una ruta de producción que involucra a diferentes actores, y esta no es responsabilidad única del docente.

En la creación de ambientes virtuales de aprendizaje, el docente se define como el experto temático; su función, en primera instancia, consiste en formular los objetivos, los contenidos y el diseño de las actividades y la evaluación en línea con los objetivos de aprendizaje de una unidad temática en particular que, posteriormente, se van a consignar en los entornos o aulas virtuales de aprendizaje; también debe ser capaz de proponer y formular el uso de herramientas digitales que permitan la participación de las tecnologías de la información y la comunicación en la práctica académica; de ahí la necesidad de que el docente alcance competencias en TIC y en la elaboración de recursos educativos digitales.

ElMinisterio deEducación Nacional(MEN), en alianza con el Ministerio de Tecnologías de la Información y Comunicaciones (MINTIC), Intel y Microsoft ha liderado itinerarios de formación docente, entre estos se encuentran:

- Maestro Digital: promueve la formación y certificación en el uso básico de las TIC de los docentes de las diferentes regiones del país.

- TemáTICas: está dirigido a directivos de instituciones educativas, con el fin de cualificar su labor y promover procesos de mejoramiento institucional apoyados con las TIC. /

- Intel Educación: Es un modelo de formación de formadores por medio de docentes que tienen un alto nivel de competencias en el uso de TIC.

- Entre Pares (Microsoft): esta metodología se fundamenta en el concepto de comunidades de aprendizaje, en el que un docente comparte su conocimiento con un par u otro docente de la misma institución.

- A Que te Cojo Ratón: está dirigido a docentes que se inician el desarrollo de las competencias de uso pedagógico de las TIC (Portal Colombia Aprende, 2014).

Si bien, tanto el MEN, como reconocidas empresas que desarrollan software y hardware, han diseñado y liderado espacios de formación para los docentes dirigidos al uso pedagógico de las TIC, hacen falta estrategias que los orienten en la integración de sus prácticas educativas en las aulas virtuales como apoyo a la presencialidad, para que estas no se conviertan en repositorios o en la expresión de "una de las tendencias generales que todavía se vive en muchas de las universidades (...) colonizar lo virtual con los textos utilizados en las clases presenciales, colgados en toda su extensión" (Prieto, 2012, p. 9); pues, no se trata solo de cambiar el soporte de enseñanza, sino de resignificar los contenidos.

\section{Los recursos educativos digitales}

Los contenidos digitales se denominan recursos educativos digitales (RED) cuando su diseño tiene una intencionalidad educativa, cuando apuntan al logro de un objetivo de aprendizaje y cuando su diseño responde a unas características didácticas apropiadas para el aprendizaje (Zapata, 2012).

Los RED deben poseer un alto grado de componentes pedagógicos para que cumplan una verdadera función formativa; no basta únicamente con exponer la información, deben incluir objetivos claros y actividades que permitan al estudiante evaluar su desempeño. 
Para la elaboración de un recurso educativo digital, en primera instancia, es necesario tener muy claro el objetivo de aprendizaje que se pretende alcanzar, la finalidad del material y el grupo objetivo al que se pretende llegar, sin dejar de lado el contexto deuso. La construcción de un recurso educativo digital nace de un componente teórico de una asignatura o de tema en particular; a ese componente teórico se le confiere un carácter pedagógico que se convierte, posteriormente, en un recurso educativo digital, a través de herramientas de computación gráfica y de diferentes lenguajes de programación, acompañados de un proceso de diseño de multimedia; para lo cual se debe tener claridad sobre los conceptos de multimedia e hipertexto.

\section{La multimedia}

Se podría afirmar que la multimedia es la integración o combinación de diferentes medios de información en un mismo soporte, según la siguiente definición:

Presentación de material verbal y pictórico, en donde el material verbal se refiere a las palabras, como texto impreso o texto hablado y el material pictórico que abarca imágenes estáticas (ilustraciones, gráficas, diagramas, mapas, fotografías) y también imágenes dinámicas (animaciones, simulaciones o videos)" (Mayer, 2005, p.2).

Para Wolfgang, el término multimedia se define desde diferentes perspectivas, desde un nivel tecnológico, que "significa el uso de múltiples medios para entregar la información (hardware), desde un nivel de formatos de representación (texto, imágenes y desde un nivel sensorial que responde al uso de los sentidos (ojos, oídos)" (como se cita en Mayer, 2005, p. 49).

En los RED, los contenidos educativos se fundamentan bajo una serie de principios de diseño multimedia, de tal manera que faciliten y agilicen el proceso de aprendizaje de los estudiantes. El aprendizaje multimedia es aquel en el que un sujeto logra la construcción de representaciones mentales ante una presentación multimedia, en otras palabras, logra construir conocimiento (Mayer, 2005).

\section{EI hipertexto}

Desde el punto de vista tecnológico, un recurso educativo digital se concibe de una estructura hipertextual (conformada por nodos y enlaces) que definen una ruta de navegación a través del contenido teórico y que se dinamiza a través de elementos de texto, imagen, audio, video, animación (multimedia).

Para articular la información de un modo no lineal, característica de los recursos educativos digitales, se recurre al hipertexto. José Luis Orihuela y María Luisa Santos (2000), en su libro Introducción al diseño digital, definen el hipertexto como:

Un sistema de escritura ramificada solo posible técnicamente en entornos digitales, que se constituye como un documento electrónico en el que se estructura como una red de nodos y enlaces. Se denomina nodo a cada unidad de información en un hipertexto (por ejemplo una página, una pantalla o una escena), y enlace o link a la conexión entre esos nodos. Al navegar el usuario activa enlaces para desplazarse entre los nodos (2000, p.38).

Los enlaces se representan a través de botones, palabras e íconos, entre otros, "la selección y combinación de las estructuras más adecuadas para cada proyecto se realiza en función de los contenidos y género de la aplicación, así como atendiendo al perfil del usuario y a la funcionalidad de la navegación" (Orihuela y Santos, 2000, p.39).

Es el caso de los recursos educativos digitales, el contenido se organiza en una estructura hipertextual, y esta se define desde un guion instruccional de acuerdo con contenido en el que se articula la información. 
Una vez articulados los contenidos en la estructura hipertextual, se integran de manera dinámica los elementos (texto, imagen, audio, video, animación, etc.) que convergerán con esta para dar como resultado una hipermedia.

En el proceso de desarrollo de la hipermedia se debe controlar la ruta de acceso a cada uno de los contenidos (nodos), de tal manera, que el estudiante los asimile de manera adecuada $\mathrm{y}$ alcance los objetivos de aprendizaje propuestos para el recurso educativo digital. Retomando la definición de hipertexto como sistema de escritura ramificada y no lineal, se puede entender que un recurso educativo digital puede ser diseñado para uno o varios objetivos de aprendizaje a la vez.

\section{Los participantes en la elaboración de un recurso educativo digital}

Un recurso educativo digital debe ser específicamente diseñado para el entorno digital. Santos, en su artículo "Organización y gestión de equipos para el desarrollo de contenidos educativos multimedia", afirma que para la elaboración de contenidos educativos es necesario contar con un equipo multidisciplinar, "la complejidad técnica, estética y narrativa, exige la participación de equipos formados por especialistas de diversas áreas" (2006, p.3), y propone que contemple los siguientes perfiles profesionales:

- Coordinador: es quién lidera el proyecto, define y verifica el cumplimiento del cronograma y de las actividades. Así mismo analiza el grupo objetivo o población a quien va dirigido el recurso educativo digital, los requisitos o necesidades, para poder establecer criterios claros en cuanto a pedagogía y diseño multimedia; es por tal motivo que el coordinador debe tener conocimiento de las responsabilidades de cada uno de los perfiles del equipo multidisciplinar.

- Asesor pedagógico: es el encargado de definir el método de aprendizaje y quien evalúa la pertinencia de los elementos que conformarán el guion instruccional (de este se hablará en el siguiente punto). Así mismo, es quien determina cuál es el método de aprendizaje más adecuado para el diseño del recurso educativo digital.

- Experto temático (docente y en quien se centra este proyecto): es quien tiene amplio dominio del tema y el encargado de elaborar el guion instruccional, en este formula los objetivos, recopila el contenido y propone las actividades de aprendizaje, así como los métodos de evaluación, "el experto aporta la documentación y referencias documentales necesarias para que los editores de formatos multimedia puedan desarrollar su tarea posteriormente" (Santos, 2006, p. 18). Los trabajos del experto temático y del pedagogo están directamente relacionados, de tal forma que si el experto temático tiene experiencia en pedagogía, puede asumir ambos perfiles.

- Diseñador gráfico y/o multimedia: apoyado en el guion instruccional que previamente ha elaborado, el experto temático, define la estructura hipertextual, el diseño de navegación y desarrolla el concepto gráfico de las interfaces, la composición y los elementos gráficos, textuales y audiovisuales que integraran la interfaz.

- Informático o programador: administra, integra y da soporte a los recursos y a las plataformas en las que se integrará el recurso educativo digital creado por el diseñador gráfico.

\section{El guion instruccional}

La finalidad de un guion instruccional es acercar al docente al diseño y producción de RED facilitando la comprensión de diferentes conceptos técnicos, tecnológicos y teóricos asociados con estos. 
Al guion instruccional también se le conoce como guion multimedia, guion didáctico y guion de contenidos. La Real Academia Española define 'guion' como el "escrito en que breve y ordenadamente se han apuntado algunas ideas o cosas con objeto de que sirva de guía para un determinado fin".

El "Guion de Contenidos" incluye la descripción completa de los contenidos de aprendizaje que incorporará el curso. (...). El documento incluye el contenido editorial íntegro del proyecto: el programa o sumario del curso, el desarrollo de los contenidos teóricos de aprendizaje, el enunciado de las prácticas, ejercicios y problemas y la descripción de los distintos formatos en los que se generarán dichos contenidos. Asimismo la documentación y referencias documentales necesarias para que los editores de formatos multimedia puedan desarrollar su tarea posteriormente (Santos, 2006 p. 18).

Para Bou, en cine, el guion es la construcción del proceso que se lleva a cabo desde la idea de una película hasta la descripción detallada de cada escena (1997, p. 42). En multimedia el guion es lo mismo, es la descripción detallada de cada escena de una aplicación. El diseño de un recurso educativo digital exige una planificación muy detallada de los elementos que lo constituirán; por lo que se puede entender el guion instruccional ('storyboard', en otros ámbitos) como el conjunto de procedimientos descritos, paso a paso, que orientan la realización de un recurso educativo digital; es un formato en el cual el experto temático con el apoyo del coordinador y del asesor pedagógico describe un grupo objetivo, formula unos objetivos de aprendizaje y define y estructura los contenidos; así mismo, se lleva a cabo una aproximación en cuanto a la descripción de imágenes, animaciones, elementos gráficos como íconos, botones, gráficos, entre otros; en este, se describe claramente cada uno de los elementos que constituirán un recurso educativo digital, en convergencia con la pedagogía, la tecnología y los procesos de enseñanza-aprendizaje.
El guion instruccional también cumple la función de orientar al diseñador gráfico con respecto a la creación del concepto gráfico o metáfora visual y la narrativa de los contenidos de cada una de las pantallas o escenas, así como las sugerencias respecto a imagen fija y en movimiento, animaciones, audio y video. "Cada pantalla se convierte en un problema de diseño que hay que resolver. Cuando una pantalla no ha sido pensada se nota enseguida" (Bou 1997 p. 47). El guion instruccional es importante porque articula y jerarquiza la información, organiza la producción y planifica la realización de un recurso educativo digital.

\section{El formato de un guion instruccional}

El guion de un multimedia en soporte informático tiene una estructura diferente, con columnas diferenciadas para imagen, sonido, texto y acciones (o interacciones). En cada una de ellas hay que identificar el recurso digital (en forma de fichero informático), así como los resultados de determinadas acciones sobre zonas específicas de la pantalla (Valverde, 2000, p.273).

Existe una gran variedad de formatos disponibles en la web para la elaboración del guión instruccional. En el sitio web http:// theelearningcoach.com/resources/storyboarddepot/ se pueden descargar, de manera gratuita, diferentes formatos editables con extensiones como .ppt o .doc y con la descripción de cada uno de los campos a diligenciar.

En la investigación que soporta este artículo se diseñó un formato propio, derivado del análisis de varios ejemplos consignados en el mencionado sitio web (ver tabla 1). 
Tabla 1.

Formato de un guion instruccional. Fuente: del autor

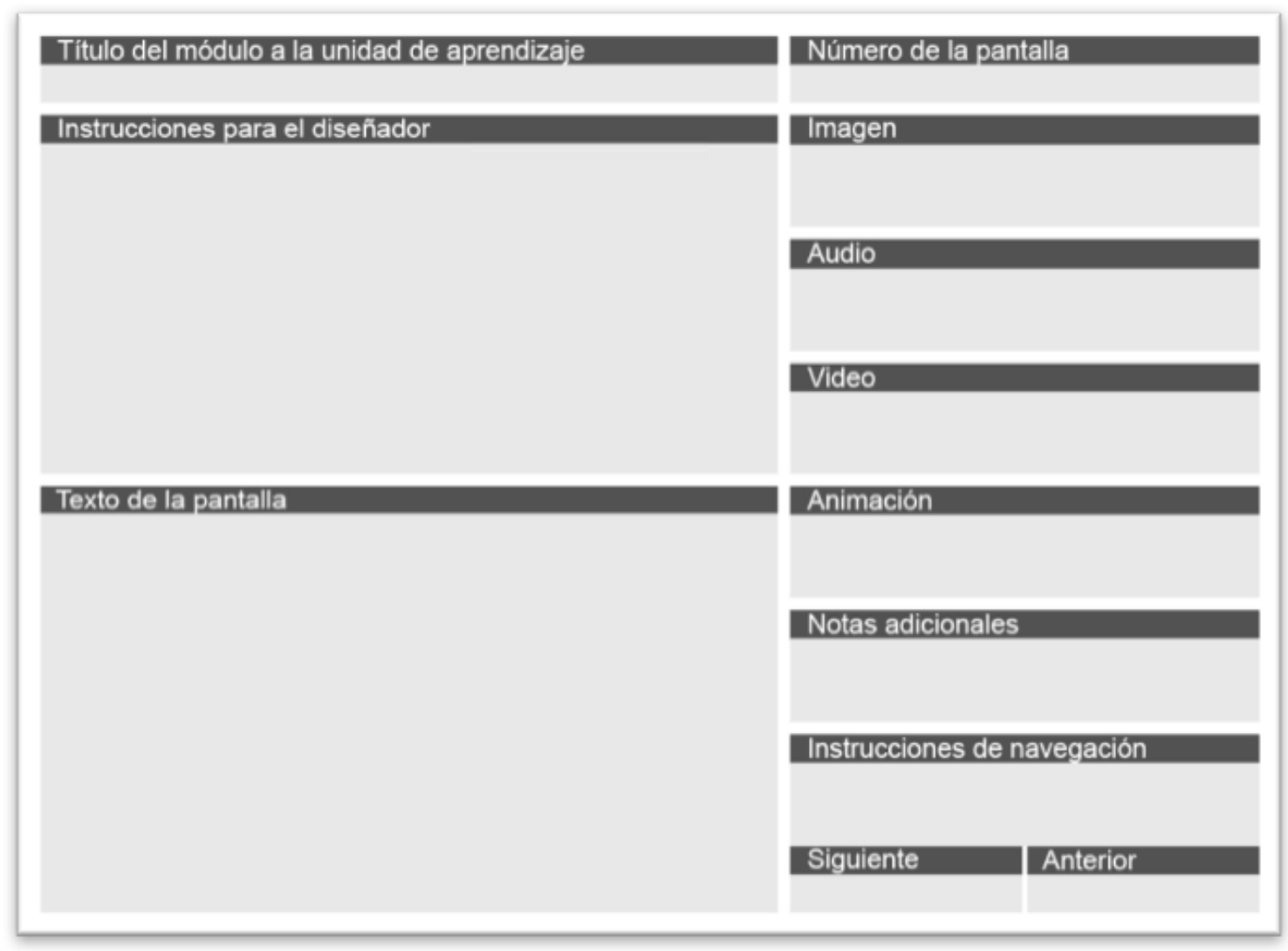

A continuación se describen cada una las áreas que conforman este formato del guion instruccional.

- Título del módulo o la unidad de aprendizaje: en este espacio se indica el módulo y/o la unidad de aprendizaje a que corresponde la pantalla.

- Instrucciones para el diseñador: en este espacio, el profesor describe los aspectos gráficos y audiovisuales que deben acompañar el contenido textual. El profesor puede proponer los elementos gráficos que se van a integrar a la pantalla como imágenes (fotos, ilustraciones, pictogramas, íconos, infografías, etc.), audio (música, narración), videos y animaciones; estas propuestas pueden ser útiles para el diseñador gráfico en la creación del material educativo digital.
- Texto de la pantalla: en este espacio se incluye el contenido textual que aparecerá en la pantalla. No se debe incluir cualquier texto incrustado en imágenes, videos, animaciones $\mathrm{o}$ en cualquier tipo de elemento gráfico que haga parte del recurso educativo digital. El contenido textual debe ser redactado en primera persona.

- Pantalla: en este espacio se deben numerar cada una de las pantallas que conformarán el recurso educativo digital, y debe hacer en el orden en que van a ir apareciendo.

- Imagen: en este espacio se deben listar, describir $\mathrm{y} / \mathrm{o}$ proponer las imágenes que deben aparecer en la pantalla; se debe indicar si es una fotografía o una ilustración, así mismo se debe indicar a cual contenido textual corresponde. 
- Audio: en este espacio se deben indicar si se requiere de algún tipo de sonido. Si es una pieza musical, se debe listar. Si se requiere de la voz de un narrador, se debe indicar si será una voz masculina o una voz femenina y se debe incluir el texto que se va a narrar.

- Video: en este espacio se debe informar si el contenido se mostrará a través de un video. Se debe indicar si el video se va a visualizar en la pantalla o si se va a acceder a este a través de un enlace, de ser este último, se debe incluir la dirección web o URL donde se aloja el video.

- Animación: en este espacio se debe describir el tipo de animación, que no solamente corresponde al contenido teórico, este aspecto también está relacionado con los elementos gráficos que hacen parte del recurso educativo digital.

- Notas adicionales: este espacio se utiliza para relacionar algún tipo de información complementaria que no está contemplada en el formato.

- Instrucciones de navegación: en este espacio se indica hacia qué pantalla avanzar o retroceder. Se deben definir claramente los diferentes trayectos de navegación dentro del recurso educativo digital. Así mismo, se deben describir e indicar las funciones de los diferentes botones como: salir, retroceder, avanzar, las zonas activas, los enlaces textuales, etc.

\section{Factores para la elaboración de un guion instruccional}

Los factores para la elaboración de este recurso son básicamente tres: consolidación de contenidos, adecuación pedagógica y definición de las pautas básicas. Estos se definen a continuación.

- Consolidación de contenidos: el primer paso para desarrollar el guion instruccional consiste en organizar la información; el tema debe estructurarse de lo general a lo particular.

- Adecuación pedagógica: se debe definir claramente la población o grupo objetivo al que va dirigido el material, los objetivos de aprendizaje, las estrategias de enseñanza y aprendizaje y las estrategias de evaluación según los objetivos que se quieren alcanzar. Este factor se desarrolla con apoyo del coordinador y el asesor pedagógico, no del diseñador gráfico.

- Definición de las pautas básicas para la elaboración del guión: para la realización de un recurso educativo digital, mínimo, se deben integrar un asesor pedagógico, un experto temático, un diseñador gráfico y un informático. En el guion instruccional, paralelamente a la organización de los contenidos, se deben describir las instrucciones relacionadas con la jerarquización de la información, las rutas de navegación dentro del recurso, el tipo de imágenes (fijas o en movimiento), el audio y el video.

\section{El guion instruccional y el aprendizaje multimedia}

En la elaboración del guion instruccional se deben tener en cuenta aspectos relacionados con las ciencias cognitivas; Mayer (2001) afirma que el aprendizaje a través de un contenido multimedia se recibe por doble canal sensitivo que corresponde a oídos y ojos. El texto se percibe como imagen, de tal manera que una pantalla que contenga texto, imagen y audio a la vez va a ocasionar que el sujeto no logre apropiarse de toda la información (carga cognitiva). Mayer(2009) propone 12 principios para el diseño de material multimedia:

Principio de coherencia: se aprende mejor cuando en un contenido multimedia no se incluyen palabras, imágenes y sonidos extraños o irrelevantes, estos se convierten en elementos distractores y generan mayor carga 
cognitiva.

- Principio de señalización: se aprende mejor cuando en el contenido multimedia se destacan o resaltan elementos importantes del contenido o las ideas principales por medio de flechas, contornos, formas, colores, entre otros.

- Principio de redundancia: se aprende mejor cuando el contenido multimedia está acompañado de elementos gráficos y narración únicamente, $\mathrm{y}$ no de elementos gráficos, narración y texto, el cerebro no puede atender los tres aspectos al mismo tiempo.

- Principio de contigüidad espacial (contextualidad espacial): se aprende mejor cuando los textos aparecen junto a las imágenes correspondientes; se debe evitar que el aprendiz realice recorridos innecesarios dentro del contenidoeducativo digital, esto genera mayor carga cognitiva.

- Principio de contigüidad temporal (contextualidad temporal): se aprende mejor cuando el texto y la imagen aparecen en una sola instancia (tiempo y espacio), de esta manera se integran a la memoria de forma simultánea, y no de forma aislada.

- Principio de Segmentación: se aprende mejor cuando el contenido multimedia se divide en módulos o secciones, esto permite que el aprendiz explore el contenido a su propio ritmo, de esta forma tendrá tiempo de procesar la información antes de avanzar a siguiente módulo o sección.

- Principio de pre-entrenamiento: se aprende mejor cuando el contenido multimedia presenta la estructura de los contenidos, así como los términos que se van a aparecer. Cada módulo o sección podría ir acompañado de un glosario de términos.

- Principio de modalidad: se aprende mejor cuando el contenido multimedia se apoya en elementos gráficos y narración, que en animación y texto. El texto en una animación se convierte en un elemento distractor debido a que ambos entran por el canal visual, esto dificulta que la información se procese adecuadamente.

Principio multimedia: se aprende mejor con texto e imagen que con solo texto, siempre y cuando las imágenes tengan el propósito de realzar el mensaje que se quiere transmitir. Al hacer uso de textos e imágenes se incrementan las conexiones mentales.

- Principio de personalización: se aprende mejor cuando un contenido multimedia hace uso de lenguaje cotidiano más que de lenguaje formal, por ejemplo, es recomendable no hablar en tercera persona.

- Principio de voz: se aprende mejor cuando el contenido multimedia es acompañado por una voz humana $\mathrm{y}$ no por una voz sintética denominada en inglés 'text-to-speech', (TTS).

- Principio de imagen (Avatar): no necesariamente se aprende mejor cuando el contenido multimedia está acompañado por un avatar (imagen del profesor/tutor).

En la aplicación de estos principios:

Hay que tener claro que la unidad básica de un documento hipertextual es la pantalla y no el papel y que por tanto no tiene por qué quedar limitado a las normas que rigen la distribución de la información en el papel (...). El objetivo del organizador de la información debe ser definir una estructura hipertextual en la que haya múltiples posibilidades de navegación en las que pueda interactuar y en las que el receptor a la vez no se desoriente ni naufrague (Ordinas, De Benito, Martí y Salinas, 1999, p.5). 


\section{Conclusiones}

La planeación docente es necesaria para el logro de los resultados formativos, y debe estar presente en todas las actividades del profesor universitario. Esta es mucho más exigente en el diseño de ambientes de aprendizaje que implican la incorporación de las TIC en el apoyo a la presencialidad. En este escenario, incluso para los profesionales capacitados, la planeación de sus cátedras se ve obstaculizada por la falta de una visión clara sobre la utilización de recursos educativos digitales.

En el ejercicio de la docencia, es necesario trabajar arduamente con los docentes por un cambio o transformación de sus prácticas educativas en el aula. Los docentes deben comprender que, en la actualidad, se requiere de nuevos esquemas y que las TIC ya están inmersas en el ámbito educativo, por lo que deben ser aprovechadas.

Existen numerosas herramientas disponibles y de uso libre para el diseño y la producción de RED como el aula virtual; sin embargo, para su implementación es imprescindible elaborar un guion instruccional para garantizar una correcta articulación de la información, organizar la producción y planificar la realización y uso de los RED, teniendo en cuenta que deben primar los aspectos pedagógicos por encima de los estéticos y que una hipermedia no es la solución a los problemas de enseñanza.

En este artículo se asume que se requiere la preparación de la comunidad educativa en el diseño y construcción de los RED a través del guion instruccional, para lo cual se describe la funcionalidad de este, así como las condiciones y factores para su elaboración, y se propone un modelo para su implementación en apoyo a las actividades de la enseñanza-aprendizaje en ambientes de aprendizaje presenciales enriquecidos por el uso de las TIC.

\section{Referencias}

\section{PMCid:PMC1565071}

Campuzano Ruíz, A. (1992). Tecnologías audiovisuales y educación. Una visión desde la práctica. Madrid: Akal.

Colombia Aprende. (2014). "Desarrollo profesional docente: itinerarios de formación docente". Recuperado de http:// www.colombiaaprende.edu.co/html/ micrositios/1752/w3-article-316666.html.

Colombia, Ministerio de Educación Nacional. (2008). Programa Nacional Uso de Medios y Nuevas Tecnologías: Ruta de apropiación de TIC en el desarrollo profesional docente. Bogotá: Autor.

Colombia, Ministerio de Educación Nacional. (2013). Competencias TIC para el desarrollo profesional docente. Recuperado de http://www.colombiaaprende.edu.co/html/ micrositios/1752/articles-318264_recurso_ tic.pdf.

Colombia, Ministerio de Educación Nacional. (2015). Decreto 1075 de 2015, por medio del cual se expide el Decreto Único Reglamentario del Sector Educación. Recuperado de http:// redes.colombiaaprende.edu.co/ntg/men/pdf/ decreto_1075_de_2015.pdf.

Laverde, A. C., Cifuentes, Y. S., \& Rodriguez, H. Y. R. (2007). Toward an instructional design model based on learning objects. Educational Technology Research and Development, 55(6), 671-681. https://doi.org/10.1007/ s11423-007-9059-0

Mayer, R. (2005). The Cambridge Handbook of Multimedia Learning. New York: Cambridge University Press, 2. https://doi.org/10.1017/CBO9780511816819

Medina, J. "El aula invertida". Recuperado de http://www.ub.edu/bonespractiquesdocents/ index.php/es/metodes-i-activitats/activitatscol-laboratives/39-el-aula-invertida.

Bou, G. (1997). El guión multimedia. Madrid: Editorial Anaya. 
Ordinas, C., De Benito, B., Martí, C. y Salinas, J. (1999). Modelos de estructuración de material didáctico multimedia utilizados en Campus Extens. Edutec, 99.

Organización de las Naciones Unidas para la Educación, la Ciencia y la Cultura. (2008). Estándares de competencias en TIC para docentes. Londres: Autor.

Orihuela, J.-L. y Santos, M.-L. (2000). Introducción al dise-o digital. Concepción y desarrollo de proyectos de comunicación interactiva. Madrid: Anaya Multimedia.

PMCid:PMC101580

Piaget, J. (1932). The moral judgment of the child. Glencoe, Illinois: The Free Press

Prieto, J. (2013). ¿Cómo dise-ar un aula virtual? Recuperado de http://joannaprieto. com/como-disenar-un-aula-virtual/.

Rúa, J. (1998). "Aproximaciones conceptuales al aprendizaje autónomo". Puntos Alternos, 4, 20-28.

Santos, M.-L. (2006). Organización y gestión de equipos para el desarrollo de contenidos educativos multimedia. Red Digital, 6, 1-21.

Valverde, J. (2000). Dise-o y elaboración de un programa educativo multimedia. En Saénz del Castillo, A. y Gómez-Galán, J (coords.). Nuevas tecnologías aplicadas a la educación. Badajoz: Universitas. 273

Zambrano J. (2008). "Crédito académico, autonomía y TIC' s". Studiositas, 3 (2), 48-59.

Zapata, M. (2012). "Recursos educativos digitales: conceptos básicos". Recuperado de http://aprendeenlinea.udea.edu.co/boa/ contenidos.php/d211b52ee1441a30b59ae008 e2d31386/845/estilo/aHR0cDovL2FwcmVuZ GVlbmxpbmVhLnVkZWEuZWR1LmNvL2 VzdGlsb3MvYXp1bF9jb3Jwb3JhdG12by5jc $3 \mathrm{M}=/ 1 /$ contenido/ 